\title{
A Continuous Bibliographic Service in University Libraries
}

IN MANY commercial, profit-making 1 organizations "literature specialists" provide the research staff with knowledge concerning the products being produced by the firm or being considered for production. Before research is started on a new project, a digest of the previous literature is made available to the research staff. Thereafter, while the research is being undertaken, information concerning new literature, or everf the literature itself, is sent directly to the research worker. With the literature of the past known to them, and the literature of the planned future being sent to them as soon as it appears, the research staff of commercial firms are au courant in their field. They can take advantage of experience or results obtained elsewhere without themselves having to expend the time or funds necessary to acquire pertinent information.

Unfortunately in universities, which are generally considered nonprofit organizations, such cooperation between the library and the research- or scholarship-producing faculty is generally nonexistent. University libraries occasionally prepare bibliographies upon request for members of the teaching and research staffs. But it is doubtful if any university library system as a whole has taken the further step of keeping such bibliographies up to date continuousty and actually bringing the material itself to the interested investigator. This article will describe such a method which was worked out for a large departmental library in a university and will attempt to draw some conclusions on the feasibility of extending the service to other parts of a university library system.

Eight years ago the library staff of the College of Physicians and Surgeons of Columbia University debated the problem of whether the principle of a continuous bibliographic service, as worked out by some commercial firms, could be introduced in a university medical library. No financial return was involved; there was no small, closely-knit group working on different aspects of the same problem nor was there the possibility of the liberal use of extra funds to start the service, which might have been the case in a nonuniversity organization. The advantages of having such a service, however, seemed so obvious that discussion centered around the means of bringing about the desired results. After much deliberation, a plan was worked out, and the then librarian was able to say in his annual report:

The outstanding event of the year 1939-40 was the establishment of a Bibliographic Service. Briefly, the library offers to supply to selected clinicians, research workers or faculty members a bibliography of a subject under investigation and to provide information concerning new material as it appears. Notice of pertinent literature is made on $3 \times 5$ " $\mathrm{P}$ " slips which are sent to the interested investigator. From time to time each recipient sends back to the library certain of the slips, which 
have been supplied, asking that the titles noted thereon be set aside for his examination at a certain hour. The material requested is placed on a table for his use. Thus, without any loss of time, red tape or signature, the doctor has pertinent literature placed at his disposal.

At the time the continuous bibliographic service was inaugurated, the staff of the library consisted of four professional assistants, excluding catalogers, and eight clerical assistants. The mechanics of the service were kept as simple as possible, both because funds were not available and because it was felt that mechanics were unimportant per se. An assistant in the reference department was placed in charge of the service and given full-time stenographic help. The assistant selected had a working knowledge of medicine and the fields which are basic to it, facility with several foreign languages, and a familiarity with medical journals and the indexing and abstracting tools in the field. Without these qualifications - and approximately in the order given-it was felt that it would be unwise to assign a staff member to work on a continuous bibliographic service. For example, such boners as including typhus fever and typhoid fever in one bibliography might conceivably occur if a "green" assistant attempted such a service.

It was decided that anyone on the teaching or research staff should be eligible for the service, subject to a review of his request by the librarian. The prospective user filled out a request form (reproduced on page 327) outlining his needs and discussed the problem with the bibliographic assistant. After the assistant had an understanding of what was desired, he further oriented himself by additional reading in some standard work or review of the problem.

A carefully selected list of some two hundred journals, including not only standard English and foreign language journals but also a large group of indexing and abstracting services, were routed to the bibliographic service as soon as they were received in the library. The bibliographic assistant examined the journals, indicating, on the basis of the subjects being followed, the titles to be typed, and the typist copied the references on $3 \times 5$ slips in the following manner :

Finger, G.

The influence on specific immune substances of sulfonamide medication.

Z. Immunitäts. I03:372-8, 1943

Abstracted in: Chem. Abstr. 39:4974, Nov, 10, 1943

B. Jones 
One copy of each bibliographic slip was sent to the particular research worker or clinician who had requested material on that subject; a carbon copy was retained in the library for use by others interested in the same subject and to prevent duplication. (Subsequently, some of the more heavily-used bibliographies were mimeographed and distributed.) When the recipient of the service wished to read any of the references sent to him, he merely returned the bibliographic slips for those articles, with a notation of the time that he planned to come to use the material. bibliographic service? An analysis of the service at the College of Physicians and Surgeons showed that the recipients fell into several distinct categories. Each category had separate needs and used the bibliographic service for a different purpose.

The largest group is composed of experts in a narrow field who need to keep up with the literature of their minute subject. Unfortunately, since their subject is so narrow, the literature appears in widely scattered places; and it is in making these experts aware of important material in obscure publications, as well as in calling to their atten-

TABLE I

\begin{tabular}{c|c|c|c}
\hline Year & $\begin{array}{c}\text { Number of } \\
\text { Subjects }\end{array}$ & $\begin{array}{c}\text { Number of } \\
\text { Individuals }\end{array}$ & $\begin{array}{c}\text { Approximate Number } \\
\text { Citations Supplied }\end{array}$ \\
\cline { 1 - 3 } $1939-40$ & Not Recorded & 36 & 5000 \\
$1940-41$ & 155 & 79 & 8500 \\
$1941-42$ & 87 & 49 & 7000 \\
$194^{-4}-43$ & 87 & 48 & 5000 \\
$1943^{-44}$ & 64 & 41 & 5000 \\
$1944-45$ & 86 & 43 & 4000 \\
$1945-46$ & 132 & 56 & 11000 \\
$1946-47$ & $135^{1}$ & $75^{1}$ & $16000^{1}$ \\
\hline
\end{tabular}

${ }^{1}$ Estimate on Mar. I, 1947.

The loan desk staff then secured the volumes and placed them on a table in the stacks, where the reader could consult them.

Other users of the service requested the assignment of a table in the stacks on which the literature could be placed when available. Thus, they were assured of seeing desired material in due course without' the annoyance of reports that requested material was "out, at bindery, missing, etc."

The numerical growth of the continuous bibliographic service at the medical library is shown in Table I.

For what purposes do members of a university community use a continuous tion translations of abstracts of foreign language works pertinent to their subject, that the continuous bibliographic service shows its special usefulness. For such individuals speed and complete coverage are the prime desiderata.

Closely allied to this group are the authors of exhaustive annual reviews or those discussions of recent advances which appear in the publications of the learned societies. An example of this is the man who lectures each year to the American Society of Clinical Medicine on the treatment of diabetes. These people, like the group mentioned above, need wide coverage of the literature, from a knowledge of 
which they can distil the important advances and discard the unimportant work. They are the ones who need the abstracts of foreign articles; and their use of them is to decide which articles should be read in toto.

\section{Authors' Use}

A third group of workers who use the continuous bibliographic service are those authors engaged in writing a monograph or textbook or revising an old edition of such a work. These people need to have at their disposal the literature of a larger span of years than the other groups mentionedusually the literature from the publication of the last edition to the present. Speed in getting material to them is not so essential as it is to the other experts; but, since these people must digest masses of material before they can write, any plan for bringing the literature directly to them without subjecting them to annoying delay and much red tape is especially appreciated.

It is this group who are the bane of the page staff's existence but who swell the statistics of the use of the library. They come to the library with a handful of bibliographic service slips-sometimes as many as fifty or sixty at a time-and request that the material be placed on a reading room table for them within a few hours. After the clerical staff has performed feats of legerdemain to produce the materials at the appointed hour, the research worker glances rapidly over the literature spread before his eyes, most of which he quickly discards as of no importance, and takes with him the three or four important items to be read thoughtfully and digested. It is this use of the bibliographic service which must be explained carefully to the nonprofessional members of the staff, in order that surly service may not negate the work of the professional staff.
The three groups already mentioned have one thing in common-for all of them the literature of the present or of a definite period in the immediate past is more important than a complete survey of all the literature. Due to the exigencies of the war, we have another such group with us, a group which will probably gradually grow smaller until it disappears completely. This is the group of workers whose normal occupations have been interrupted by a period of war service far from the literature of their field. Upon their return they feel the need for finding out what has been done in their absence. These individuals want shortterm, intensive help; and the bibliographic service can be particularly useful in locating exhaustive reviews of their fields for themthe same kind of article which the continuous bibliographic service is helping the second group of users of the service, described above, to write.

These four groups then, are the ones most interested in the new literature: the expert in a narrow field, the author of an exhaustive review article, the individual writing a book, and the person back from the war. Two other large groups make use of such a continuous bibliographic service: the clinician with a case of a new or rare disease and the research worker contemplating a new research project.

\section{Complete Reviews}

These last two groups are distinct from the other groups previously mentioned in that their interest is retrospective rather than current. These are the people who want to know everything that has been written on their particular subject, without any especial interest in whether it was written two thousand years ago or last week. The clinician wants to know if anybody at any time has ever described a case similar to the one confronting him, and, 
if so, how it was treated and what was the outcome. The research worker wants to know whether anybody has ever worked on the same problem he has in mind-and he wants to know it before he starts on long, elaborate, and often costly work which might easily duplicate the work of others. A complete review of the literature is the only answer to these questions.

By some it might be argued that such a review of the literature does not constitute a continuous bibliographic service; while this is partially true, certain facts must be borne in mind. The same techniques used for compiling the material in one kind of bibliographic service are used for the other; in the bibliographic service being described in this paper, the reader and the literature are brought together expeditiously, so that the trained investigator is left free to use his brain for the work he was trained to dothe understanding of the contents of the literature-rather than having to spend his time in library routines. Just as the expert mentioned above knows a large segment of all the information on the treatment of diabetes, so the librarian should be the expert in a knowledge of the subject bibliographic tools. A medical librarian who knows only the Index-Catalogue of the Army Medical Library and the Quarterly Cumulative Index Medicus, for example, is no more of an expert than the physician who has read only Gray's Anatomy.

There are several justifications for such a service, some tangible, others intangible. Over 5000 journals are published currently in medicine and its related fields, and of these the medical library of Columbia University receives about 1300 . If it were possible for a member of a university to devote regularly an hour a day to library reading, he could follow some twenty or thirty of these journals. However, each of these journals must be gone over separately to pick out articles pertinent to his work and he must, perforce, let the other 1270 pass without a glance. Of course, there is always the possibility that an occasional reference, footnote, or quotation will lead him to valuable information elsewhere, but, as a systematic approach to the coverage of any given field, this method leaves much to be desired.

\section{One Person Covers Field}

In sharp contrast to this hit-or-miss method, it has been found that a welltrained, properly qualified library assistant, spending four hours daily on the bibliographic service, can adequately examine over two hundred journals regularly, keeping a sharp eye out for articles relating to approximately one hundred subjects at the same time. By including indexing and abstracting journals, as well as journals which contain both original articles and abstracts, the number of journals read by table of contents can and does run close to the one thousand mark.

No single individual using this specialized approach for his own information could possibly afford the amount of time such a system requires. No educational institution or research group could afford to have members of its highest-paid faculty and research staff each spending a fairly large proportion of his time doing such routine checking of indexes. Faced with these facts, the effciency and economy of treating the whole matter as a library function becomes rather obvious.

It is conservative to say that from within a week to a month after publication most articles are brought to the attention of the investigator. The advantage thus gained is a definite asset when considered in the light of the three- to six-month period the Q.C.I.M. takes to index current -medical literature, or the year to eighteen months it 
takes the Current List, Chemical Abstracts, or Biological Abstracts to issue their subject indexes. Consequently, the continuous bibliographic service has proved itself valuable in reducing to a minimum that all-important factor, the "time element."

The advantages of a continuous bibliographic service are that: it is faster than the published indexes; it is timesaving, in that the same actions are done for a large number of individuals simultaneously rather than separately for each person; and it provides more complete information than any individual could afford to amass for himself. The disadvantage is that the library assistant in charge of selecting the literature is rarely, unfortunately for the library profession, as well-trained in the subject field as the investigator.

A continuous bibliographic service has been found to be successful at Columbia University for the subject fields of medicine and its cognate sciences. Should it not be adapted to other subjects? There seems to be no reason why such a service could not be taken over in its entirety by most scien-

\section{COLUMBIA UNIVERSITY MEDICAL LIBRARY}

College of Physicians and Surgeons

630 West 168th Street

\section{BIBLIOGRAPHICAL SERVICE}

The Medical Library compiles bibliographies for members of the staff of the Medical Center. This service is rendered upon request when assistance is desired in the writing of books and papers, in the reporting of unusual cases, or, what is perhaps more important, as an accompaniment to the study of the problems encountered in practice or experimental research. There is no charge for the service.

References to the literature are supplied on $3 \times 5$ slips suitable for filing. Wherever possible notes are included showing where abstracts may be found. If desired the reference slips may be used in lieu of requisition for the articles. If 24 hours notice is given, such articles will be segregated for use at one of the tables in the stacks or reading room.

In compiling bibliographies, the published medical indexes, the collections of medical abstracts and the various review journals (English and foreign) are consulted, supplemented by the checking of current literature in the library.

\section{BLANK FOR OUTLINING SUBJECT OF INVESTIGATION}

Subject of Investigation

Phases of the subject to be covered by investigation (Please check):

$\begin{array}{lll}\text { Case histories } & \text { Etiology } & \text { Prognosis } \\ \text { Diagnosis } & \text { Historical review } & \text { Symptomatology } \\ \text { Differential diagnosis } & \text { Pathology } & \text { Treatment }\end{array}$

Terms (or synonyms) under which material may be found:

Years to be covered ......... Languages to be covered: All except

Only

Signed

Telephone Extension

Approved 
tific libraries within a university framework -zoology, chemistry, engineering, and physics, for example. All that is needed is a substitution of the appropriate indexing and abstracting tools and periodicals for those used in medicine.

\section{Could Serve Other Fields Too}

The authors believe such a bibliographic service could also be set up in departmental libraries serving the creative arts, the humanities, and the social sciences. All that is needed is a library with an adequate collection, especially in current publications, and a subject-trained library staff.

University librarians are increasingly conscious of the great mass of scholarly literature which pours into their libraries and is carefully cataloged, classified, and subject-headed, only to sit on the shelves untouched. It is generally recognized that one of the greatest impediments to the advancement of learning at the present time is the lack of effective means by which the findings of scholars-especially those of diverse nations and languages - can be brought to light, mobilized, and put to work. The conclusion is inescapable that the libraries of the world must in the future play a far more decisive role than at present in increasing the productivity of research. One of the major ways in which university libraries can contribute is through the establishment of a continuous bibliographic service for the scholars requiring their active support. 